Article

\title{
Users' Choice in Providing Services to the Most Vulnerable Homeless People
}

\author{
Inger Lise Skog Hansen \\ Fafo Institute for Labour and Social Research, 0608 Oslo, Norway; E-Mail: ilh@fafo.no
}

Submitted: 6 April 2018 | Accepted: 4 July 2018 | Published: 28 September 2018

\begin{abstract}
Several municipalities in Norway have tried the Housing First model to facilitate permanent housing for homeless people with substance abuse problems and/or mental illness. This article discusses users' experiences from receiving social support as part of the Housing First programme. In particular, the article discusses the users' experiences with the model's emphasis on users' choice and self-determination. The analysis shows that what the programs practise is not entirely freedom of choice for the participants but a greater respect of the users' knowledge, perspectives, and opinions as a starting point for interventions. The analysis shows that participants and staff engage in joint reflection work to help the participants take more reflected decisions in their life. The article discusses how this method can contribute to overcome a diagnostic approach to marginalised and often stigmatised users and provide more personalised and effective services. The discussions draw on data from an evaluation of two trial projects of the Housing First model. The article is mainly based on an analysis of 16 qualitative interviews with users that participated in the projects.
\end{abstract}

\section{Keywords}

drug problems; homelessness; Housing First; mental illness; Nordic model; user experience; user participation; welfare state

Issue

This article is part of the issue "Vulnerable and Disadvantaged Groups: On the Margins of the Welfare State?", edited by Inger Lise Skog Hansen and Tone Fløtten (Fafo Institute for Labour and Social Research, Norway).

(C) 2018 by the author; licensee Cogitatio (Lisbon, Portugal). This article is licensed under a Creative Commons Attribution 4.0 International License (CC BY).

\section{Introduction}

The Nordic welfare states are conventionally known as generous and service-intensive welfare states. Comparatively, these welfare states are characterised by high levels of welfare and wellbeing. However, there are "blind spots" in terms of securing the welfare of all individuals. Persons with substance abuse problems and mental illness are often in risk of ending in these blind spots and not receiving the services and support they need, with a higher risk of experiencing homelessness and living at the margins of society (Dyb \& Lid, 2017; Hansen \& Øverås, 2007).

The American model Housing First (Tsemberis, 2010) is today one of the most profiled models for addressing homelessness in Europe (Busch-Geertsema, 2013; Pleace, 2016). The model was developed in New York for homeless people with mental illness and addiction and as an alternative to a more common continuum of care model, or "treatment first" model. This is often described as the "staircase model" (Sahlin, 2005). The user has to "qualify" for independent housing while proving step by step that they will be able to cope with living in ordinary housing. The Housing First model approaches housing as a fundamental right and a prerequisite for further recovery. Users are moved quickly into permanent housing in ordinary neighbourhoods and provided floating follow-up support from a multidisciplinary team. The model strongly emphasises users' choice to support the users' own recovery process. The original Pathways to Housing (PTH) model (Tsemberis, 2010) had eight core principles: 1) housing as a basic human right; 2) respect, warmth, and compassion for all clients; 3 ) a commitment to work with clients as long as they need it; 4) scatteredsite housing and independent apartments; 5 ) the separation of housing and services; 6 ) consumer choice and selfdetermination; 7) a recovery orientation; and 8) harm 
reduction. The Housing First model is presented as an evidence-based model (Pleace, 2016; Tsemberis, 2010). While several studies have shown effectiveness related to rehousing homeless people with high support needs and achieving greater housing retention, the effects in relation to recovery, drug use, and social integration are questioned (Groton, 2013; Kirst, Zerger, Misir, Hwanga, \& Stergiopoulos, 2015; Pleace, 2011; Quilgars \& Pleace, 2016).

Since 2012, there have been several local Housing First projects in Norway (Andvig, Bergseth, Karlsson, \& Kim, 2016; Andvig \& Hummelvoll, 2015; Hansen, 2017; Snertingdal \& Bakkeli, 2015). Mappings of Housing First projects in Europe, as in Norway, have revealed that there are variations between projects labelled as Housing First, both related to target groups, housing solutions, and follow-up models (Busch-Geertsema, 2013; Pleace, Culhane, Granfelt, \& Knutagård, 2015; Snertingdal \& Bakkeli, 2015). In Norway, the Housing First projects have mainly been targeted at homeless people with substance abuse problems and/or mental illness (Snertingdal \& Bakkeli, 2015) - this in contrast to, for example, the Housing First program in Finland that has had a broader target group (Pleace et al., 2015), or in Lisbon where the target group has been persons with mental illness (BuschGeertsema, 2013).

In this article, I discuss users' experiences from participating in Housing First programs in Norway.

\section{Background}

The article is based on data from an evaluation of two Housing First trial projects that took place in the municipality of Bergen and the municipality of Sandnes, in Norway, from 2014 to 2016 (Hansen, 2017). Both used the PTH, the original American Housing First model (Tsemberis, 2010), as their starting point.

In Norway, a housing-led strategy has been the main policy in combating homelessness for many years (Benjaminsen, Dyb, \& O'Sullivan, 2009; Hansen, 2006). The shift from treatment first to greater emphasis on harm reduction, housing, and follow up services for homeless people with drug problems started at the turn of the millennium. Still, municipalities experience challenges in providing housing and services for the most vulnerable homeless people. The last mapping of homelessness showed a significant reduction in the number of homeless persons (Dyb \& Lid, 2017) but revealed that almost six in ten of those who are homeless are drug addicts, and one in four have a dual diagnosis of mental illness as well as substance abuse (Dyb \& Lid, 2017, p. 69). This situation is one of the reasons why this group of homeless people has been the target group for Housing First interventions in Norway.

The evaluation of the two local Housing First projects in Norway found a housing retention rate of approximately 70\% (Hansen, 2017). This is lower than in many other Housing First projects in Europe and a possible explanation is that this is due to the inclusion of a target group with severe challenges related to substance abuse and mental illness. The evaluation states that the participants express great satisfaction with their housing situation, but it is not able to identify any concrete results in terms of the participants' recovery when it comes to mental health issues, substance abuse problems, and social integration. Many of the participants claim to have a better life than before, albeit realising that they still face major challenges in their life (Hansen, 2017).

The way the Housing First model has been operationalised in the two projects closely resembles the American model described by Tsemberis (2010). In one key respect, however, both Housing First teams differ from the model: neither includes a doctor or a psychiatrist, as did the Assertive Community Treatment (ACT) teams that were involved in the original programme in New York. The Norwegian teams are more similar to case-management teams including nurses, social workers, and counsellors. Both teams had sufficient resources to provide closer follow up than ordinary support services. The evaluation revealed that the Housing First teams provide a broad range of services, including various forms of practical assistance, help with personal finances, counselling on various issues, help to establish and maintain contact with other social and health services, and coordination of service provision on an individual basis. Those who are recruited to the Housing First project and choose to participate must meet fundamental demands: they have to accept to receive follow-up services and a home visit by the team once a week and the participant must not be assessed a danger to him/herself or others (Hansen, 2017).

As pointed out, the evaluation of the two programs is not able to identify that the Housing First model has led to positive effects when it comes to the recovery and social integration of the participants. In this article, I consider as a starting point that the projects have succeeded in recruiting and rehousing a group of homeless people with severe substance abuse problems and/or mental illness. Their housing situation is more stable than before and they receive follow-up services. I am occupied with the users' perspective on what they perceive as different from earlier housing and follow-up services they have received and how the core element of freedom of choice and self-determination are perceived from their perspective.

\subsection{Analytical Approach}

In this article, I explore the relationship between service providers, the front line of the welfare state (Lipsky, 1980), and service users with drug problems and mental illness. My main attention is how the service users perceive the services they receive and their relationship with the service providers. I pay special attention to how the participants experience the model's emphasis on users' choice. Emphasis on housing as a prerequisite for further recovery and users' choice as a method 
to support the users' own recovery could be argued to have the same diagnostic view of users as the "treatment first" approaches. Hansen Löfstrand and Juhila (2012) have discussed the discourse of consumer choice in the Housing First Manual (Tsemberis, 2010). They point out that choice making is not an end goal, but a means to achieve recovery (Hansen Löfstrand \& Juhila. p. 62). The Housing First manual has the professionals' view of "correcting" the user and helping them make "right" choices, not "bad" ones. There is an acceptance of failures, but there are limits to how many times a person can fail and not learn from their failures (Hansen Löfstrand \& Juhila. p. 62). In the analysis, I explore how the participants experience their interactions with the service providers and their practise of the core element user's choice.

Having drug problems and mental health issues could represent a stigma (Goffman, 1975). A stigma indicates that something is labelled deviant from what is normal in society, discredited, and something that needs to be corrected or treated. When meeting with service providers, mental health problems or drug problems might be stigmas that overshadow all other qualities of the person and, from the perspective of the service providers, something that should be "cured". As an example, Grut (2003) has pointed out that professionals may tend to interpret what people with mental health issues or drug problems tell in light of their condition or diagnosis. In a study of a trial project on user participation in mental health services, she found that establishing a systematic way of collecting the opinions and experiences of the users awakened the professionals' tendency of a diagnostic approach to the users' opinions and influencing the attitudes of the professionals regarding the users' ability to contribute in service development (Grut, 2003). In the analysis, I use the concept of stigma to explore the effect of drug problems and mental health issues in the interaction between service providers and users.

In the relationship between professionals and clients, power is not equally distributed. Professionals have, through their professional knowledge and exercise of discretion in relation to different interventions and measures, more power in the relationship than clients (Lipsky, 1980). The emphasis on consumer choice in Housing First could be analysed in view of recent developments in welfare policy towards increased user involvement, transfer of power, and co-production of services (Needham \& Carr, 2009; Torfing, Sorensen, \& Roiseland, 2016).

In the following, I use the term "participants" instead of "service users" for the people that receive follow up from the Housing First teams. The term is used in the Housing First projects, stressing that "participants" are participating out of free will and in a form of partnership with the team.

\section{Methods and Data}

The analysis is based on data from an evaluation of two local trial projects of the Housing First model (Hansen,
2017). In this article, I mainly draw on qualitative interviews with 16 participants in the two projects: 13 men and three women. Most of the participants in the two Housing First projects are men, and men are also overrepresented among those who are homeless in Norway (Dyb \& Lid, 2017). The youngest informant was under 30 years old, nine were between 30 and 49 years old, and the six remaining informants were over 50 years old. The interviews followed an interview guide and the main topics were how they had been recruited to the Housing First project, why they wanted to participate, their housing situation at the time and before they entered the projects, the services they receive and experiences with them, their relation to the Housing First staff, their assessment of the services they receive compared to earlier experiences with welfare services, and finally, general questions about how they feel (quality of life). All the interviews except for one were taped and later transcribed before further thematic analysis was generated from the research questions of the evaluation (Patton, 1990). For the purpose of this article, I organised the empirical data from the interviews with the participants in thematic matrices for further analysis. The topics of the matrices are related to the participants' motivation for joining the program, their relationship with the service providers, experiences with the philosophy of users' choice and self-determination.

The informants were recruited through the staff in the Housing First projects. The staff distributed written information about the evaluation and the participants later reported to staff or the research team if they wanted to be interviewed. Two researchers were involved in carrying out the interviews and both were careful to underline that participating in the evaluation was voluntary and that what the participants told or did not tell the researchers would be treated as confidential and have no consequences for the services they receive. The informants were guaranteed full anonymity.

Three of the interviews with the participants were done at the informants' houses, one interview was done at an inpatient detox centre, and one was conducted by telephone. The eleven remaining interviews were carried out in an office at the location of the Housing First team. As part of the evaluation, the two researchers spent two days together with the Housing First projects. This provided an opportunity to observe the service providers at work, observe the staff relate to participants when they met them, and observe the participants in interactions with the staff when they came by the office. The field trips and interviews were carried out in November and December of 2016. The study is approved by the Norwegian Centre for Research Data.

People with drug problems and mental health issues are a vulnerable group. Ethical reflections have been important in reporting on the evaluation and in writing this article. I have been careful about how information from the interviews has been used and presented in order to not contribute to the further stigmatisation of a group 
already experiencing marginalisation in society. This is a vulnerable group facing marginalisation in many areas, so it is important that their voices, perspectives, and experiences are heard and studied. To secure anonymity, I do not identify which of the two projects the informants participated in or state their age and sex. When quoting from the material, the number of the informants is stated.

\section{Findings}

\subsection{Access to Housing}

The main motivation for joining the Housing First project for all of the informants was the chance to get their own dwelling. One of the informants tells that when he first met the Housing First team he thought that his chance of getting a place to stay on his own was very limited. He did not have any references; he was afraid of going to public viewings and was, in general, anxious about the whole situation. Others tell about similar experiences. Some have lived periods in tents in different camping cabins or other occasional places, or with friends and family. Gaining access to ordinary housing based on their preferences is particularly important. This must be seen in the perspective that many of the participants have had earlier experiences of not being in a position to choose a dwelling on their own premises due to substance abuse problems or other social and health problems. One of the participants tells that he was provided municipal housing in a housing complex with several persons with active drug use and a lot of noise and trouble going on. He was anxious and afraid of staying in this place. He tells us: "I knew that this would not work. I told them. Nevertheless, I was placed there. They have to listen to me! I was going to stay there, achieve well-being, and thrive" (Informant 16).

Throughout the analysis, we observed that most of the informants had experienced that in meeting with the municipal social housing system, there was not allowed much room for their personal preferences. A program that offers access to ordinary housing according to your own preferences then becomes attractive. A common reference by the participants is that this is very different from what they had experienced before. In the first phase after the participants are taken into the Housing First program, there are several talks between staff members and the participants about how they want to live and what is important to the person when it comes to housing and follow-up from the team. This quote illustrates a common experience: "They asked me how I wanted to live. How my situation was, what I wanted, how my dream house would look" (12).

What the participants want, and what they perceive as important for his or her housing situation varies. Some of the participants emphasise that the flat is not placed on the first floor, others that the building they stay in has a gate or an entrance that make it possible for them to protect themselves from unwanted visitors. Some want to live in the centre of town, others find it crucial to have a flat just outside the city centre or away from areas with drug consumption. A common reference is the importance of being listened to and having their opinions taken seriously when it comes to where they want to live.

\subsection{Respect and Acceptance}

The analysis reveals that most of the informants have gained a new kind of relationship with the welfare services compared to what they had experienced before. What the participants often stress as different from experiences with ordinary services is the way they are approached by the staff. When asked what is good about the Housing First project, one of the participants immediately answers: "The way they are". Another informant stresses that "the staff met [them] in a humane way, in a friendly way, not as part of a system or as in an institution" (12).

The process of recruiting participants involves one or more meetings between the Housing First team and potential candidates to consider whether they shall receive an offer to join the program. The staff meet with potential participants and talk about what the Housing First project is, what it would involve for the person participating, and ask the candidate why he or she eventually wants to participate. This creates a foundation of further collaboration between staff and participant. The team has been floating in their approach from the beginning. The staff have arranged to go for a walk in a park, go for a drive or talk together in places the candidate chose. Many of the informants talk about the way they were met in these first meetings; that the team made it easy to meet, that the staff were easy to talk to, and how this contributed to them wanting to join the project. A common reference from the participants about staff members is that "they are kinder. They try to understand things" (10).

Another participant expresses the pattern when describing how the relationship with the staff is different from other relationships with professionals he has experienced:

You get closer to them [staff members]. It is not an office, it is more inclusive. When you meet them, you can tell that they are glad to see you. They see behind your behaviours, see the person in this....You feel worthy when you meet them, that you are of importance. (11)

The analysis shows that several of the participants in meeting with the welfare services have experienced that their way of living is stigmatised, and they have felt that they are considered unworthy of the time and respect of service providers. One of the informants tells us that he had experienced that if you do not do as the service providers recommend, you will get punished in the system. All the participants have a long history of contact 
with different welfare services. Many of them have experiences of not being able to live up to expectations, rules, or criteria in different programs or activities they have been enrolled in. When they "failed", they would end up being excluded from the programs. Some participants express distrust in the general welfare services due to these experiences. A common issue is the appreciation of the tolerance and a supportive attitude from the staff. Several participants address that in the Housing First project they are allowed to say no without ending up with nothing at all. For example, they can turn down an apartment if they do not think it is the right place to live without the risk of ending up at the end of a waiting list. One participant describes what is different in the approach in this way: "They are not someone that comes to punish, but to support" (13).

Another informant expresses some of the same appreciations:

I have always had big problems with authority. These folks do not behave as authorities even though they have a lot of authority. They have a lot to say, they can just clap their hands and say, 'we do not want him in that flat', and I have to leave. (5)

The analysis shows that a factor brought up by several of the participants is the way they are met by the staff if they have had a situation when they were on drugs, or something went out of hand and was unpleasant. The experience of not risking punishment or expulsion from the program has contributed to establishing greater trust in the relationship with the service provider. Several describe that they have experienced that the staff do not withdraw from a challenging situation but meet them with respect and tolerance. One of the participants states:

They do not judge, I feel that I can speak to them about everything, which is very important. They are very liberal people. I have gained great trust in them. They could learn a bit from that in other parts of the support system. (13)

Several state that the staff are respectful while at the same time use a lot of humour and are generally in a good mood. One of the participants says: "One becomes fond of these folks; do not get away from that. They are smiley, happy, and you are met with respect" (2).

The analysis shows that elements like the acceptance of the participant, respect for their situation and perspectives in the follow-up are important for the participants. The analysis in many ways reveals that the Housing First team have succeeded in establishing a position to provide support to a group that has previously had problems in their relationship with welfare services. A harm-reduction approach without practicing sanctions of "unwanted" behaviours contributes to gaining this position.

\subsection{Floating and Flexible}

The Housing First teams have had resources to provide closer and more active support of the participants than ordinary housing support services. The analysis reveals that the participants appreciate the floating and flexible services. A common reference is about how the staff members are present in different situations, accompany them in meeting with other services, and help them with things that they ask for. One participant states that just knowing that he can contact the staff is important: "It makes me feel safe just to know I have them as backup. I can call them, and they will show up" (9).

Another participant says the following:

They know how I am. They have learned to know me. If I say, 'do not come this week', they can turn up anyway and tell me that they are here for me, and when they leave it is good to get a hug. (12)

The fact that the staff come by, whether contacted or not, represents security for many of the informants. As described in the first section, the participants are not allowed to choose not to have contact with the Housing First team. It is a condition for participating in the program to accept a weekly home visit. This constitutes a framework for the relationship. Some of the informants share that in some periods they have received follow-up several times a week. Others express that they do not need as much support at this time and have less contact.

\subsection{Joint Reflection Work}

Freedom of choice is a core element of the Housing First model. The analysis reveals these choices are not made in a vacuum but most often a result from what could be described as joint reflection work. The staff members and participants engage in reflection on different situations and choices to be made. This is an illustrative quote from this kind of collaboration between the actors: "I tell them what I feel and think, they say what they think, and we always agree in a way. There are no discussions, arguing, or grumpiness" (7).

One tool in engaging in this joint reflection work is the collaboration on establishing a safety plan on how the participant wants to collaborate with the Housing First team; what kind of services the participants want to receive and how they want to be treated if different situations should occur. How they want to be treated if they get into a period when they are very ill if they have relapses or periods with heavy drug use. Where the staff should look if they are worried and do not find them at home, whom they should contact etc. Making these plans is an important joint task of the participant and staff in the first phase of participation in Housing First. The analysis indicates that this process is based on joint reflection more than what could be described as 
freedom of choice. The analysis shows that the staff contribute with advice, guidance, questions, and opinions.

The analysis shows that the freedom of choice is not necessarily easy to handle for the participants. Making choices demands a more active engagement in several areas. Some of the informants express a kind of ambivalence to this freedom of choice. Some do not always feel that it is easy to make decisions. The statement from one participant when asked about how he experiences the core element of freedom of choice illustrates this ambivalence:

I think they can decide a little too, I am not very good at deciding. Sometimes I do not know what I need. But I have come up with some specific things that have been organised and we have agreed on something they are to take care of that has to do with my economy and paying the rent. (12)

The Housing First projects have more resources than other services to engage in reflection with the participants. For example, when a participant has challenges regarding neighbours and keeping a stable housing situation, the staff can engage in a process with the participant reflecting on what the problem is, what can be done, and what they can learn from these experiences. One informant tells that he has had some experiences since he got his first apartment regarding what he needs to keep the apartment. The joint reflections with the team have been useful in order to understand what is needed to deal with several of the challenges he faces. Still, he is very confident that he keeps control and makes the decisions regarding his life. Another informant addresses that there have to be some limits to users' freedom of choice:

I have appreciated the possibility to make my own choices. I have. But there is something about making an active substance abuser the administrator of his own life. That will not work. So, I understand the need for a team to back you, but they cannot back you on things that are totally horrible. It has to be things related to recovery, for substance abusers to get away from substance abuse. To help you get into town to buy drugs would be wrong. (8)

This informant describes that he thinks of the staff members as counsellors that give guidance when it comes to making choices. The analysis shows a common pattern of staff members engaging as active partners in what I have labelled joint reflection work. One precondition of the participants' appreciation of this involvement is the staff members' attitude towards their perspectives and opinions. The previously described tolerance, respect, and acceptance form a platform for this joint reflection work.

\section{Closing Discussion}

Housing is a fundamental basic need. Getting access to ordinary housing has motivated homeless people with severe substance abuse problems and mental illness to join the Housing First programs. In joining the program, the participants have agreed to regularly receive support from the Housing First team. The analysis presented shows the importance of a housing-led strategy that is able to provide services to this vulnerable group with complex needs. The analysis reveals that participants experience that the practice of tolerance by the staff members, being treated with respect and acceptance, and having their perspectives and opinions acknowledged is of vital import regarding their engagement in the program.

Having a harm-reduction approach without sanctioning unwanted behaviours as a starting point is important for gaining the trust of the participants. This trust is important for further cooperation and joint reflection work. The analysis has illustrated that drug problems and mental illness can be a stigma in meeting with the welfare services. The stigma becomes a barrier for being listened to or taken seriously when in need of services. The emphasis on respect and acknowledging users' opinions in the approach towards participants, in the same way, could contribute to professionals overcoming a diagnostic approach and, by listening to the participants, provide more personalised and user-oriented services.

The joint reflection work could be seen as in line with the general trend in welfare services changing from delivery to the co-production of services. The users are given a more prominent role in defining their own services and this might lead to more effective service provision. The method implies that the professionals have to engage in listening to and, if necessary, help the participant express his or her needs and opinions. The professionals have to put aside some of their professional knowledge and power to make the participant take control. Having to reflect on your own needs, wants, and wishes could contribute to the greater empowerment of participants and in so promote better recovery. The analysis reveals that the participants' opinions and preferences are heard and that their personal knowledge is acknowledged. Engaging in making choices is not always easy and most of the participants appreciate the staff members as partners or co-producers of decisions. The analysis shows that freedom of choice is accompanied by guidance from the staff in this joint reflection work. The approach challenges the hegemony of the professional knowledge but does not represent that the principle of freedom of choice is fully realised. The analysis in this article shows that participants acknowledge that their relationship with the service providers is not based on equal distribution of power and, to a large degree, appreciate the involvement of the staff in their decision-making. As such, this method may resemble systemised user involvement more than a liberal consumer choice.

The Housing First projects in Norway have succeeded in rehousing a vulnerable group of homeless people with complex needs. The evaluation of the projects does not identify evidence for better results when it comes to re- 
covery so far (Hansen, 2017). The Norwegian programs have mainly had an ICM model in their follow-up; but having a target group with severe substance abuse problems and mental illness might indicate a need for providing more specialised health services in the teams (as an ACT model). The policy implications from this analysis contribute to discussions on the possibility of gaining a larger degree of empowerment and co-production of services in housing and services for the most vulnerable homeless people, resulting in more personalised and effective services.

\section{Acknowledgments}

This article is based on data from an evaluation conducted on commission from Health West, Regional Health Authorities, Norway. Colleague Vidar Bakkeli has participated in the evaluation project.

\section{Conflict of Interests}

The author declares no conflict of interests.

\section{References}

Andvig, E., \& Hummelvoll, J. K. (2015). From struggling to survive to a life based on values and choices: Firstperson experiences of participating in a Norwegian Housing First project. Nordic Journal of Social Research, 6(2005), 167-183.

Andvig, E., Bergseth, A., Karlsson, B., \& Kim, S. H. (2016). Med brukeren i førersetet? En forskningsbasert evaluering av Drammen kommunes prosjekt «Ditt valBolig først» [With the user in front? An evaluation of the project "Your choice-Housing First" in the municipality of Drammen] (Report 3). Drammen: Centre for Mental Health and Addiction. Faculty of Health Sciences, University College of South-Eastern Norway.

Benjaminsen, L., Dyb, E., \& O'Sullivan, E. (2009). The governance of homelessness in liberal and social democratic welfare regimes: National strategies and models of intervention. European Journal of Homelessness, 3(December), 27-55.

Busch-Geertsema, V. (2013). Housing first Europe final report. Brussels: European Union.

Dyb, E., \& Lid, S. (2017). Bostedsløse i Norge 2016 [Homeless people in Norway 2016] (Report 2017:13). Oslo: Norwegian Institute for Urban and Regional Research.

Goffman, E. (1975). Stigma. Om afvigerens sociale identitet. [Stigma. Notes on the managemen of spoiled identity] København: Nordisk forlag AS.

Groton, D. (2013). Are housing first programs effective? A research note. The Journal of Sociology \& Social Welfare, 40(1), 51-63.

Grut, L. (2003). En modell for brukermedvirkning i psykiske helsetjenester. Brukermedvirkning: Et poli- tisk prinsipp og et praktisk virkemiddel. [A model for user involvement in mental health services. User involvement: A political principle and a practical measure]. Tidsskrift for Velferdsforskning, 6(3), 178-188.

Hansen, I. L. S. (2017). Fra bostedsløs til varig bolig. Evaluering av forsøk med Housing first $i$ Bergen og Sandnes [From homelessness to permanent houing. Evaluation of two projects based on the Housing First model in Bergen and Sandnes] (Report 2017:06). Oslo: Fafo.

Hansen, I. L. S. (2006). The pathway to a permanent home. The Norwegian strategy to prevent and combat homelessness (Working Paper 2006:22). Oslo: Fafo.

Hansen, I. L. S., \& Øverås, S. (2007). Bolig for personer med psykiske lidelser og rusproblematikk [Housing for persons with mental health problems and substance abuse]. In E. Brodtkorb \& M. Rugkåsa (Eds.), Under tak-mellom vegger. Perspektiver på boligens betydning i velferdsstaten. Oslo: Gyldendal Akademisk.

Hansen Löfstrand, C. H., \& Juhila, K. (2012). The discourse of consumer choice in the pathways to housing first model. European Journal of Homelessness, 6(2), 47-66.

Kirst, M., Zerger, S., Misir, V., Hwanga, S., \& Stergiopoulos, V. (2015). The impact of a housing first randomized controlled trial on substance use problems among homeless individuals with mental illness. Drug and Alcohol Dependence, 146, 24-29.

Lipsky, M. (1980). Street level bureaucracy: Dilemmas of the individual in public service. New York, NY: Rusell Sage Foundation.

Needham, C., \& Carr, S. (2009). Co-production: An emerging evidence base for adult social care transformation (SCIE Research Briefing 31). London: Social Care Institute for Excellence.

Patton, M. Q. (1990). Qualitative evaluation and research methods ( $2 \mathrm{nd}$ ed.). Thousand Oaks, CA: Sage Publications.

Pleace, N. (2011). The ambiguities, limits and risks of housing first from a European perspective. European Journal of Homelessness, 5(2), 113-127.

Pleace, N. (2016). Housing first guide Europe. York: University of York. Retrieved from homelesshub.ca/ sites/default/files/HFG_full_Digital.pdf

Pleace, N., Culhane, D., Granfelt, R., \& Knutagård, M. (2015). The Finnish homelessness strategy. An international review. Helsinki: The Ministry of the Environment.

Sahlin, I. (2005). The staircase of transition: Survival through failure. Innovation: The European Journal of Social Science Research, 18(2), 115-136.

Snertingdal, M., \& Bakkeli, V. (2015). Housing first $i$ Norge-Sluttrapport. Prosesser, resulateter og kartleggingsskjema [Housing First in Norway: Final report. Processes, results and mapping form]. (Report 2015:52). Oslo: Fafo. 
Torfing, J., Sorensen, E., \& Roiseland, A. (2016). Transforming the public sector into an arena for cocreation: Barriers, drivers, benefits, and ways forward. Administration \& Society. Advance online publication. https://doi.org/10.1177\%2F0095399716680057

Tsemberis, S. (2010). Housing first: The pathways model to end homelessness for people with mental illness and addiction. Center City, MN: Hazelden.

Quilgars, D., \& Pleace, N. (2016). Housing first and social integration: A realistic aim? Social Inclusion, 4(4), 5-15. http://dx.doi.org/10.17645/si.v4i4.672

\section{About the Author}

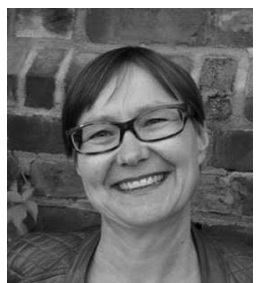

Inger Lise Skog Hansen is a Sociologist and Researcher at Fafo Institute for Labour and Social Research, Oslo. Her main research interests include social policy, welfare services, services for vulnerable groups, and social inclusion. Hansen has carried out several studies related to housing and support services to persons with drug problems and mental health issues. Among her ongoing projects is a process evaluation of the governmental Escalation plan for the field of drugs and addiction. 